\title{
An Unusual Presentation of Tarsal Tunnel Syndrome Caused by an Inflatable Ice Hockey Skate
}

\author{
B.V. Watson, H. Algahtani, R.J. Broome, J.D. Brown
}

\begin{abstract}
Background: Tarsal tunnel syndrome is a rare form of entrapment neuropathy. In athletes, it is usually the result of repetitive activity, local injury or a space-occupying lesion. Rarely, athletic footwear has been described as the primary cause of this syndrome. Methods: A 37-year-old male recreational hockey player was examined clinically and electrophysiologically because of spreading numbness in the toes of his left foot while playing hockey and wearing inflatable ice hockey skates designed to promote a better fit. Results: Clinical and electrophysiological studies revealed evidence of left medial and lateral plantar nerve involvement. Reduced amplitudes of mixed and motor plantar nerve responses with fibrillation potentials and positive sharp waves and no evidence of conduction block suggest that the primary pathology was axonal loss. Follow-up examination showed significant clinical and electrophysiological improvement after the patient stopped wearing his inflatable ice hockey skates. Conclusion: We report an unusual case of tarsal tunnel syndrome caused by an inflatable ice hockey skate. The patient improved clinically and electrophysiologically when he stopped wearing the boot.
\end{abstract}

RÉSUMÉ: Une présentation inusitée de syndrome du canal tarsien causé par un patin de hockey sur glace gonflable. Introduction: Le syndrome du canal tarsien est une forme rare de neuropathie de compression. Chez les athlètes, il résulte habituellement de l'activité répétitive, d'une blessure locale ou d'une lésion compressive. Il est rare que les chaussures athlétiques soient la cause principale de ce syndrome. Méthodes: Un homme âgé de 37 ans, joueur de hockey récréatif, a subi une évaluation clinique et électrophysiologique parce qu'il présentait un engourdissement des orteils de son pied gauche pendant qu'il jouait au hockey avec des patin de hockey sur glace gonflables, conçus pour un meilleur ajustement. Résultats: Les études cliniques et électrophysiologiques ont montré une atteinte du nerf plantaire interne et externe gauche. Une diminution de l'amplitude des réponses mixtes et motrices du nerf plantaire, avec des potentiels de fibrillation et des ondes abruptes positives sans évidence de bloc de conduction, suggèrent que la pathologie primaire était une perte axonale. Le suivi a montré une amélioration clinique et électrophysiologique significative quand le patient a cessé de porter ses patins de hockey gonflables. Conclusion: Nous rapportons le cas inusité d'un syndrome du canal tarsien causé par un patin gonflable. La condition clinique et électrophysiologique du patient s'est améliorée quand il a cessé de porter les patins.

Can. J. Neurol. Sci. 2002; 29: 386-389

Tarsal tunnel syndrome (TTS) is a rare entrapment neuropathy caused by compression of the distal portion of the tibial nerve beneath or distal to the flexor retinaculum. Most cases are idiopathic. ${ }^{1-3}$ Besides trauma, which is the most common cause, other etiologies include compression, biomechanical and systemic disorders. ${ }^{4}$ Symptoms may include aching, burning, tingling, numbness, or cramping in the plantar region of the foot that can be exacerbated by prolonged walking or standing. ${ }^{2,4}$ There may be impaired sensation, muscle weakness, and atrophy in the distribution of the medial and lateral plantar nerves. Tarsal tunnel syndrome in athletes is usually the result of repetitive activity causing tenosynovitis, ${ }^{5}$ local injury or space occupying lesions. ${ }^{6,7} \mathrm{We}$ present the clinical and electrophysiological features of a hockey player with suspected TTS caused by compression of the tibial nerve by an inflatable ice hockey skate boot.

From the Department of Clinical Neurological Sciences, London Health Sciences Centre, University Campus, London, Ontario, Canada.

ReCeIVEd February 18, 2002. ACCEPTED IN FINAL FORM June 3, 2002. Reprint requests to: JD Brown, London Health Sciences Centre, University Campus, Department of Clinical Neurological Sciences, 7th Floor - Room 7OF1, 339 Windermere Road, London, Ontario, Canada, N6A 5A5 


\section{CASE Report}

A 37-year-old male, recreational hockey player developed numbness in the third toe of his left foot that ultimately spread to the remaining toes. These symptoms were provoked by inflating his skate boot with two pumps whose reservoirs were located below the medial and lateral malleoli (Figure 1). Symptomatic relief was obtained immediately by releasing the air pressure from the reservoirs. Four years earlier he had a $1 \mathrm{~cm}$ osteochondral fracture of the superomedial aspect of the left talar dome and recovered fully following arthroscopic surgery involving removal of a loose fragment and debridement for osteochondritis dissecans. Examination two months after the onset of his symptoms revealed decreased pin-prick appreciation in the distribution of the left medial and lateral plantar nerve territories. He had a positive Tinel's sign inferior to the medial malleolus. The remaining examination was normal with no evidence of nerve hypertrophy. X-rays of the left foot and ankle revealed mild osteoarthritic changes in the ankle joint with no other significant bony abnormalities.

\section{Electrophysiological studies}

Electrophysiological studies were performed at two and 3.5 months following the onset of symptoms. Standard nerve conduction study techniques were used for the posterior tibial and deep peroneal motor nerves, and for the medial and lateral plantar mixed nerves (orthodromic), sural (antidromic) and superficial peroneal (antidromic) sensory nerves. ${ }^{8}$ Concentric needle electromyography was graded as per Miller et al. ${ }^{9}$ Motor point stimulation of the medial plantar nerve was used to assess conduction block across the left tarsal tunnel. The right medial and lateral plantar nerves were studied for comparison. The nerve

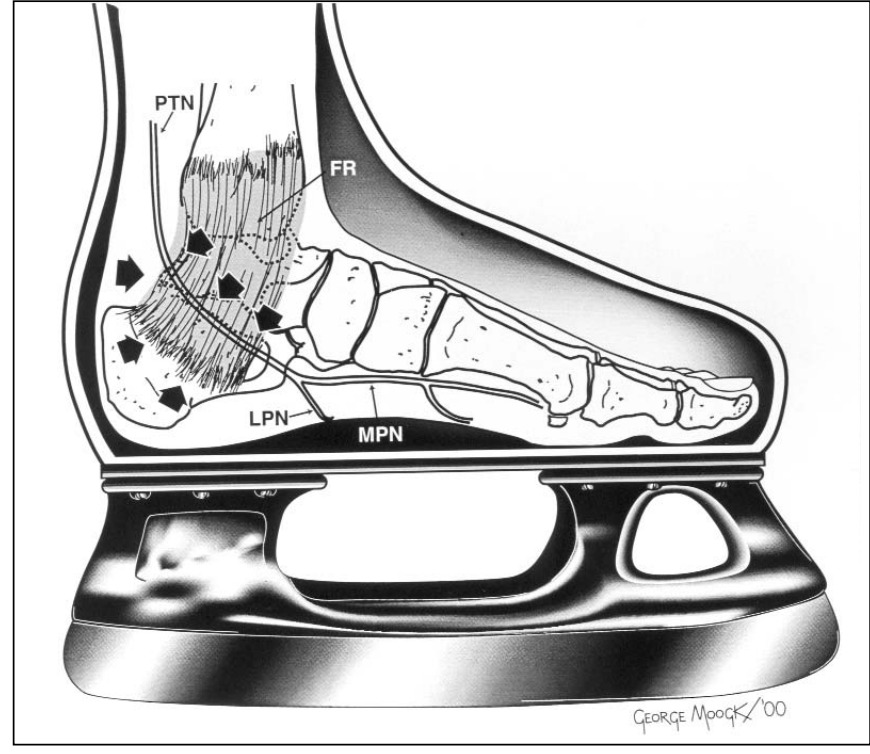

Figure 1: Arrows indicate the proposed site of increased air pressure on the left tibial nerve as it passes behind and distal to the medial malleolus. Symbols: PTN, posterior tibial nerve; FR, flexor retinaculum; LPN, lateral plantar nerve; MPN, medial plantar nerve.

conduction study results from the initial and follow-up examinations are shown in the Table.

Table: Nerve Conduction Studies

\begin{tabular}{|c|c|c|c|c|c|c|c|c|c|c|}
\hline \multirow[t]{2}{*}{ Nerves } & \multicolumn{6}{|c|}{2 Months post-onset } & \multirow[b]{2}{*}{$\begin{array}{c}\text { NP Area } \\
(\mathrm{mVms})\end{array}$} & \multicolumn{3}{|c|}{ 3.5 Months post-onset } \\
\hline & \multicolumn{2}{|c|}{$\begin{array}{l}\text { Latency } \\
\quad(\mathrm{ms})\end{array}$} & \multicolumn{2}{|c|}{$\begin{array}{c}\mathbf{C V} \\
(\mathbf{m} / \mathbf{s})\end{array}$} & \multicolumn{2}{|c|}{$\begin{array}{c}\text { NP Amplitude } \\
(\mu \mathrm{V} \text {-sensory) } \\
(\mathrm{mV} \text {-motor) }\end{array}$} & & 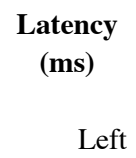 & $\begin{array}{l}\begin{array}{l}\mathbf{C V} \\
(\mathbf{m} / \mathbf{s})\end{array} \\
\\
\text { Left }\end{array}$ & $\begin{array}{c}\text { NP Amplitude } \\
\text { ( } \mu \text { V-sensory) } \\
\text { (mV-motor) } \\
\text { Left }\end{array}$ \\
\hline \multicolumn{11}{|l|}{ Mixed Nerve Conduction } \\
\hline Medial Plantar Nerve & 4.1 & 2.9 & 36.6 & 51.0 & 1.7 & 12.8 & & 3.7 & 40.5 & 7.6 \\
\hline Lateral Plantar Nerve & NR & 2.8 & NR & 54.3 & NR & 8.2 & & 3.6 & 42.2 & 2.9 \\
\hline \multicolumn{11}{|l|}{ Sensory Nerve Conduction } \\
\hline Sural Nerve & 2.3 & & 43.5 & & 13.7 & & & & & \\
\hline Superificial Peroneal Nerve & 2.2 & & 45.5 & & 36.7 & & & & & \\
\hline \multicolumn{11}{|l|}{ Motor Nerve Conduction } \\
\hline \multicolumn{11}{|l|}{ Posterior Tibial Nerve (AH) } \\
\hline \multicolumn{11}{|l|}{ Deep Peroneal Nerve (EDB) } \\
\hline ankle & 3.9 & & & & 7.0 & & & & & \\
\hline fibular head & 11.4 & & 42.4 & & 6.1 & & & & & \\
\hline popliteal fossa & 13.3 & & 45.3 & & 6.1 & & & & & \\
\hline
\end{tabular}

Legend: $\mathrm{ms}$, milliseconds; $\mathrm{m} / \mathrm{s}$, metres per second; $\mu \mathrm{V}$, microvolts; $\mathrm{mV}$, millivolts; $\mathrm{mVms}$, millivolt.millisecond; NR, no response; $\mathrm{AH}$, abductor hallucis; EDB, extensor digitorum brevis; $\mathrm{CV}$, conduction velocity; NP, negative peak 
2 MONTHS POST-ONSET

(B) PLANTAR NERVES

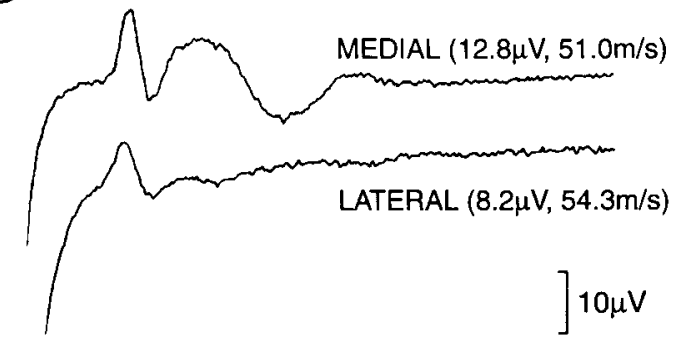

(L) PLANTAR NERVES

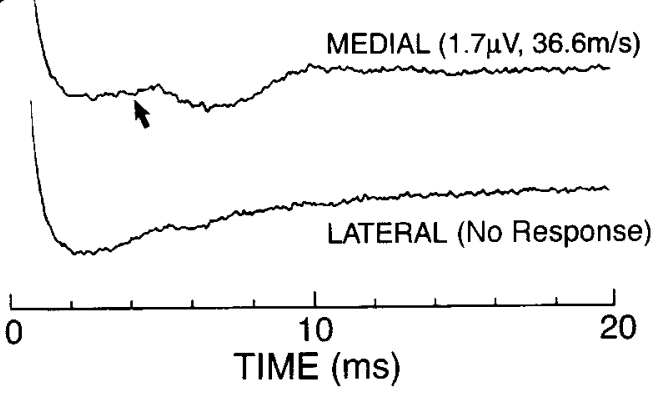

3.5 MONTHS POST-ONSET

(A) PLANTAR NERVES

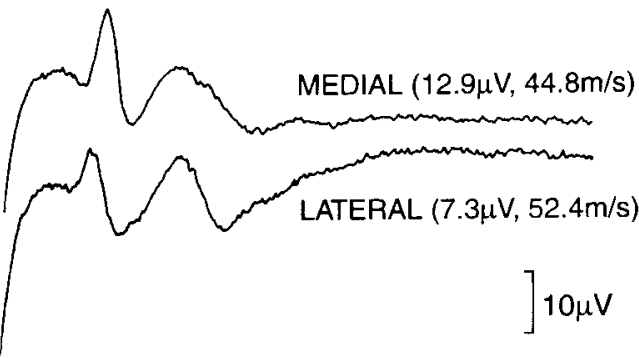

(L) PLANTAR NERVES

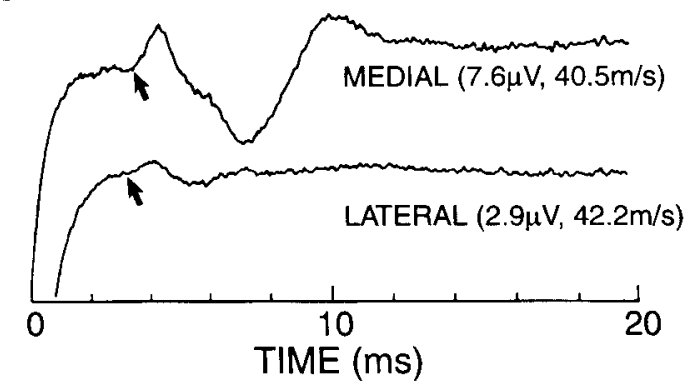

Figure 2: Represents the right and left medial and lateral plantar mixed nerve conduction studies done at two and 3.5 months following the onset of symptoms. Note the marked reduction in the left medial plantar negative peak amplitude when compared to the right side at two months. The left lateral plantar response was absent. At 3.5 months post-onset, there was significant improvement in the left medial and lateral plantar responses. Conduction velocities improved to within normal limits (arrows indicate the onset of the left medial and lateral plantar mixed nerve responses).

Two months post-onset: The left medial plantar mixed nerve response and conduction velocity was markedly reduced compared to the right side (Figure 2). No response was recordable from the lateral plantar nerve. The left posterior tibial nerve distal motor latency and maximum motor conduction velocity between the popliteal fossa and the ankle were normal. The left abductor hallucis muscle negative peak amplitude was reduced compared to the right side. There was no evidence of conduction block between the motor point and proximal to the tarsal tunnel. Concentric needle electromyography revealed fibrillation potentials and positive sharp waves in the left abductor hallicus muscle (3+) and in the left abductor digiti minimi muscle (1+). Occasional early recruited, large amplitude motor unit potentials and reduced recruitment patterns were observed in both muscle groups. Nerve conduction studies of the deep peroneal, sural and superficial peroneal nerves were normal. The combined clinical and electrophysiological examinations suggested a distal lesion of the left medial and lateral plantar nerves consistent with a diagnosis of tarsal tunnel syndrome.

Three and one-half months post-onset: Immediately after he stopped wearing his hockey skates, following his first assessment, the patient's symptoms improved significantly. Importantly, he did not develop any symptoms while wearing roller blades and running shoes. Examination at this time revealed only a small sensory disturbance to pin-prick located beneath the left medial malleolus. A Tinel's sign was still present. Electrophysiological studies revealed significant improvement in the left medial plantar mixed nerve response and the presence of a lateral plantar mixed nerve response (Figure 2). The left abductor hallucis negative peak amplitude response had improved slightly. Needle electromyography of the plantar foot muscles revealed early recruiting large amplitude, polyphasic motor units but no evidence of abnormal spontaneous activity. The recruitment patterns had improved but they were still modestly reduced. The tibialis posterior, medial gastrocnemius and tibialis anterior muscles were normal.

\section{Discussion}

Tarsal tunnel syndrome refers to entrapment of the posterior tibial nerve beneath the flexor retinaculum or to one of its three terminal branches (calcaneal, medial plantar and lateral plantar) located in the distal tarsal tunnel. Symptoms include intermittent aching, cramping, numbness, tingling or burning pain in the ankle and/or the foot. ${ }^{2,4,10,11}$ Prolonged standing, walking or running may exacerbate the symptoms. ${ }^{6,7}$ Complaints of weakness are uncommon. ${ }^{2,4}$ Clinically, there may be impaired sensation with weakness and atrophy in the territory of the medial and lateral plantar nerves with possible involvement of the medial calcaneal nerve. A Tinel's sign is often present at the compression site. $2,4,7,10,11$ When TTS occurs in athletes it usually presents with radiating burning or sharp shooting pains and paresthesias originating at the ankle. ${ }^{5,7}$ Our case of a recreational hockey player presented only with numbness in the third toe, 
which ultimately spread to the remaining digits. He denied any symptoms of radiating pain or paresthesias.

Ill-fitting footwear or tight casts are the most common causes of external compression in TTS. ${ }^{12,13}$ Other causes include focal foot trauma, tumours, tenosynovitis, bony deformities, ganglion, anomalous or hypertrophied foot muscles, fibrous bands, varicosities, biomechanical dysfunction, and a variety of systemic diseases, which promote nerve entrapment. ${ }^{4}$ Tarsal tunnel syndrome has also been reported in athletes, particularly in runners and mountain climbers. ${ }^{5-7,11,14-18}$ As well, ski boots have been implicated in the development of TTS. ${ }^{11,19,20}$ Our case is an example of suspected TTS caused by a hockey skate with inflatable bladders designed to promote a better fit. His remote history of left ankle surgery is unlikely to be directly contributory to his symptoms as he made complete clinical recovery and X-rays of the left foot and ankle at the time of our assessment revealed only mild osteoarthritic changes.

In electrophysiological studies of TTS, sensory or mixed nerve conduction studies are more likely to be abnormal than motor conduction studies.,11,21,22 Initially, our case showed a significant reduction in the left medial and lateral plantar mixed nerve amplitudes with mildly slowed conduction velocities. The left abductor hallucis negative peak amplitude was only modestly reduced. Repeat studies 1.5 months later, after the patient stopped wearing his hockey skates, demonstrated significant improvement in the medial plantar sensory response and modest improvement in the abductor hallucis response.

In the rare instances when TTS is present, it is more likely to show electrophysiological changes of axonal loss rather than focal demyelination..$^{23}$ The reduced motor and sensory negative peak amplitudes without electrophysiological evidence of motor conduction block and the observation of fibrillation potentials and positive sharp waves suggest that in our case the primary pathology was axonal. It is possible that there may have been conduction block in the mixed plantar nerve studies across the tarsal tunnel, however, the electrophysiological concerns of phase cancellation outweighed any attempts to accurately quantify this possibility. ${ }^{8}$ In our case, the mechanisms responsible for injury were likely mechanical compression and ischemia, although it is difficult to determine the relative contribution of each. ${ }^{24-26}$

\section{Conclusion}

We report a rare case of suspected TTS caused by an inflatable ice hockey skate. The patient improved clinically and electrophysiologically when he stopped wearing the boot. Importantly, the patient continued to remain active without provoking symptoms of TTS while wearing other sport footwear.

\section{ACKNOWLEDGEMENT}

The authors thank Mr. George Moogk for the artwork and Ms. Cathy Stuart for the photography.

\section{REFERENCES}

1. Radin EL. Tarsal tunnel syndrome. Clin Orthop 1983; 181:167-170.

2. Oh SJ, Meyer RD. Entrapment neuropathies of the tibial (posterior tibial) nerve. Neurol Clin 1999; 17(3):593-615.

3. Cimino WR. Tarsal tunnel syndrome: review of the literature. Foot Ankle Int 1990; 11:47-52.

4. Dumitru D. Focal peripheral neuropathies. In: Electrodiagnostic Medicine. Philadelphia: Hanley \& Belfus, Inc., 1995:905-908.

5. Lorei MP, Hershman EB. Peripheral nerve injuries in athletes: treatment and prevention. Sports Med 1993; 16(2):130-147.

6. Hainline B. Nerve injuries. Med Clin North Am 1994; 78(2):327-343.

7. Schon LC. Nerve entrapment, neuropathy, and nerve dysfunction in athletes. Orthop Clin North Am 1994; 25(1):47-59.

8. Kimura J. Electrodiagnosis in Diseases of Nerve and Muscle: Principles and Practice. 3rd ed. New York: Oxford University Press, Inc., 2001.

9. Miller RG, Peterson GW, Daube JR, Albers JW. Prognostic value of electrodiagnosis in Guillain-Barre syndrome. Muscle Nerve 1988; 11: 769-774.

10. DeLisa JA, Saeed MA. The tarsal tunnel syndrome. Muscle Nerve 1983; 6:664-670.

11. Jackson DL, Haglund B. Tarsal tunnel syndrome in athletes: case reports and literature review. Am J Sports Med 1991; 19(1):61-65.

12. Ward PJ, Porter ML. Tarsal tunnel syndrome: a study of the clinical and neurophysiological results of decompression. J R Coll Surg Edinb 1998; 43(1):35-36.

13. Bailie DS, Kelikian AS. Tarsal tunnel syndrome: diagnosis, surgical technique, and functional outcome. Foot Ankle Int 1998; 19(2):65-72.

14. Henricson AS, Westlin NE. Chronic calcaneal pain in athletes: entrapment of the calcaneal nerve? Am J Sports Med 1984; 12:152-154.

15. Hirasawa Y, Sakakida K. Sports and peripheral nerve injury. Am J Sports Med 1983; 11(6):420-426.

16. Murphy PC, Baxter DE. Nerve entrapment of the foot and ankle in runners. Clin Sports Med 1985; 4(4):753-763.

17. Rask MR. Medial plantar neurapraxia (jogger's foot). Clin Orthop Rel Res 1978; 134:193-195.

18. Schon LC, Baxter DE. Neuropathies of the foot and ankle in athletes. Clin Sports Med 1990; 9(2):489-509.

19. Antonini G, Gragnani F, Vichi R. Tarsal tunnel syndrome in skiers. Case report. Ital J Neurol Sci 1993; 14(5):391-392.

20. Yamamoto $S$, Tominaga Y, Yura S, Tada $H$. Tarsal tunnel syndrome with double causes (ganglion, tarsal coalition) evoked by ski boots. Case report. J Sports Med Phys Fitness 1995; 35(2):143-145.

21. Galardi G, Amadio S, Maderna L, et al. Electrophysiologic studies in tarsal tunnel syndrome. Diagnostic reliability of motor distal latency, mixed nerve and sensory nerve conduction studies. Am J Phys Med Rehabil 1994; 73:193-198.

22. Oh SJ, Sarala PK, Kuba T, et al. Tarsal tunnel syndrome: electrophysiological diagnosis. Ann Neurol 1979; 5:327-330.

23. Wilbourn AJ. Two uncommon nerve entrapment disorders: thoracic outlet syndrome and tarsal tunnel syndrome. AAN 52nd Annual Meeting, Apr 29-May 6, 2000, San Diego, California; Course \# 2DS.010.

24. Yates SK, Hurst LN, Brown WF. The pathogenesis of pneumatic tourniquet paralysis in man. J Neurol Neurosurg Psychiat 1981; 44:759-767.

25. Fowler TJ, Danta G, Gilliatt RW. Recovery of nerve conduction after a pneumatic tourniquet: observations on the hind-limb of the baboon. J Neurol Neurosurg Psychiat 1972; 35:638-647.

26. Fullerton PM. The effect of ischaemia on nerve conduction in the carpal tunnel syndrome. J Neurol Neurosurg Psychiat 1963; 26:385-397. 